\title{
Computer tool to evaluate the cue reactivity of chemically dependent individuals
}

\author{
Meire Luci da Silva ${ }^{a, *}$, Annie France Frère ${ }^{b}$, Henrique Jesus Quintino de Oliveirac, \\ Helio Martucci Netoc ${ }^{c}$ Terigi Augusto Scardovelli ${ }^{c}$ \\ a Universidade Estadual Paulista Júlio de Mesquita Filho, Faculdade de Filosofia e Ciências, Av. Hygino Muzzi Filho 737, Marília, São Paulo, Brazil \\ ${ }^{\mathrm{b}}$ Universidade Braz Cubas, Av. Francisco Rodrigues Filho 1233, Mogi das Cruzes, São Paulo, Brazil \\ ${ }^{c}$ Universidade de Mogi das Cruzes, Núcleo de Pesquisas Tecnológicas, Av. Dr. Cândido Xavier de Almeida e Souza 200, Mogi das Cruzes, São Paulo, Brazil
}

\section{A R T I C L E I N F O}

\section{Article history:}

Received 12 February 2016

Revised 31 October 2016

Accepted 23 November 2016

\section{Keywords:}

Computer tool

Anxiety

Cue reactivity

Chemically dependent

\begin{abstract}
A B S T R A C T
Background and objective: Anxiety is one of the major influences on the dropout of relapse and treatment of substance abuse treatment. Chemically dependent individuals need (CDI) to be aware of their emotional state in situations of risk during their treatment. Many patients do not agree with the diagnosis of the therapist when considering them vulnerable to environmental stimuli related to drugs. This research presents a cue reactivity detection tool based on a device acquiring physiological signals connected to personal computer. Depending on the variations of the emotional state of the drug addict, alteration of the physiological signals will be detected by the computer tool (CT) which will modify the displayed virtual sets without intervention of the therapist.

Methods: Developed in 3ds Max® software, the CT is composed of scenarios and objects that are in the habit of marijuana and cocaine dependent individual's daily life. The interaction with the environment is accomplished using a Human-Computer Interface $(\mathrm{HCI})$ that converts incoming physiological signals indicating anxiety state into commands that change the scenes. Anxiety was characterized by the average variability from cardiac and respiratory rate of 30 volunteers submitted stress environment situations. To evaluate the effectiveness of cue reactivity a total of 50 volunteers who were marijuana, cocaine or both dependent were accompanied.

Results: Prior to CT, the results demonstrated a poor correlation between the therapists' predictions and those of the chemically dependent individuals. After exposure to the $\mathrm{CT}$, there was a significant increase of $73 \%$ in awareness of the risks of relapse.

Conclusion: We confirmed the hypothesis that the CT, controlled only by physiological signals, increases the perception of vulnerability to risk situations of individuals with dependence on marijuana, cocaine or both.
\end{abstract}

(C) 2016 Elsevier Ireland Ltd. All rights reserved.

\section{Introduction}

Chemical dependence is characterized by a set of psychophysiological phenomena that develop with the repeated use of a psychoactive substance. The main symptoms are compulsion and loss of control. According to the World Health Organization (WHO), chemical dependence is a progressive and fatal disease, though it is treatable. However, treatment is a slow and painful process that is full of obstacles. Several researchers [1] have shown that no specific effective treatment exists for cocaine dependence but several

\footnotetext{
* Corresponding author.

E-mail addresses: meire@marilia.unesp.br (M.L.d. Silva), af.slaets@uol.com.br (A.F. Frère), quintino@umc.br (H.J.Q.d. Oliveira), heliomn@umc.br (H. Martucci Neto), terigi@gmail.com (T.A. Scardovelli).
}

medications marketed for other indications have shown efficacy in clinical trials.

Recently, researchers in Brazil have shown that the relapse rate for chemically dependent individuals (CDI) is high, occurring with $50 \%$ of individuals in the first 6 months and $90 \%$ in the first year [2]. Similar situation occur in treatment of depression, where 1 in 3 patients does not fully recover even after several treatment trials [3-5]. In addition, the American Psychiatric Association [6] states that the first 12 months of remission are considered a high-risk period. These high relapse rates indicate that the current treatment approaches still need adequate methodological advances.

According to [7] and [8], there are different risk situations that lead to the relapse of chemically dependent individuals. Recently, researchers $[9,10]$ observed that relapse can be reduced decreasing stress. Others [11,12] demonstrated that situations that might 
originate negative feelings would favor a self-rejection as well as dependents' indiscipline during treatment. Among the negative emotions, anxiety would act as a trigger to the use of drugs by the chemically dependent individuals to satisfy "temporally" their needs [13-15]. The use of psychoactive substances can be a fugue of personal conflicts, negative emotions, or stressors [16]. But can also influence the development trajectory of the symptoms of anxiety [17].

However, chemically dependent individuals often do not believe that they are vulnerable to certain external stimuli. The disagreement between patient and therapist on factors that could favor relapse [18], along with the optimal therapeutic approach, is a typical topic of discussion [19]. One of the greatest challenges for therapists is to help patients' recognize their anxiety in a risk situation without provoking them. But, the relapse triggers are questioned and are rarely accepted by the patients. The relapse generates an emotional discomfort that associated with feelings of mistrust, interpersonal stress and deprivation of liberty; contribute to the denial of chemical dependency [19]. These facts highlight the importance of self-awareness of his vulnerability. Therefore, cue reactivity procedures were used to raise chemical dependent's awareness in avoiding relapses. The cue-reactivity procedure exposes addicted to stimuli related to drugs while monitoring their physiological signals [20-22]. This method based on the conditioning theory of Pavlov $[23,24]$ shows that coping skills can be taught. Initially real environments and simulations with actors were used, but currently virtual environments are used.

Virtual cue reactivity has been used as promising interventions in anxiety disorders [25] as well as to assist during treatment of cocaine and crack cocaine [26], methamphetamine [27], alcohol $[20,28,29]$, and marijuana [30] addiction. Some researchers [31] use the procedure to nicotine users. These cue reactivity methods have provided relevant results during the treatment of chemically dependent individuals. The chemically dependent individuals experiencing anxiety in risk situation presents physical symptoms that are controlled by the autonomic nervous system, such as breathing difficulties and palpitations.

Several researchers [32-35] have demonstrated that changes in physiological signals are intrinsic associated with emotions. Other researchers [36] reported that some emotions such as stress could be detected by measuring the patient's physical and physiological signals. Since the physiological signals are involuntary were used them in this study to directly control the actions in the CT without any other intervention. In our proposed computer tool (CT), changes in the scenarios were directly produced by the patient's emotional state and not by a peripheral factor such as a joystick, keyboard, or mouse, which removes doubt and subjectivity from the results. Thus, patients are presented to virtual scenarios that are direct consequences of their emotions during risk situations, such as the exposure to drugs and familiar conflicts. In this way, the dependents can be confronted with their own evaluation regarding its anxiety and vulnerability without creating a conflict with the therapist.

\section{Method}

\subsection{Ethical approval}

Approval was obtained from the Local Ethics Committee (Research Ethics Committees from University of Mogi das Cruzes, CAAE-0094.0.237.000-07, process CEP/UMC-093/2007). All procedures were performed after written informed consent from all participants. The study is registered at https://clinicaltrials.gov/show/ NCT02535858.

\subsection{Study participants}

Eighty volunteers were engaged to realize this research.

First we determined the limits of emotional the normal and anxious states of a first group (VG) of thirty volunteers. As inclusion criteria stands out: age range between 20 and 50 years, have no disease associated with anxiety or mental disorders and not being a drug user or taking medication.

One trained psychiatrist and two mental health professionals (PG1), specialized in chemical dependency, evaluated the emotional state of the volunteers.

A second group with fifty male's adults (CDG) was selected to test the computer tool having as inclusion criteria: age range between 20 and 50 years with diagnosed dependence of marijuana, cocaine or both, in treatment for chemical dependence, not taking medication and abstaining from psychoactive substance for at least 2 months.

For this group, two psychiatrists and five mental health professionals therapists (PG2) specialized in chemical dependency and responsible for monitoring the group's treatment evaluated their emotional states.

Exclusion criteria for all volunteers were: present evidence of consumption of medicines or drugs, present psychotic symptoms or have made any physical effort before the test. The evaluation for inclusion and exclusion of volunteers was conducted by doctors responsible for the clinic who were not involved in the research. The inclusion criteria were performed using the ICD-10 protocol [37].

To elaborate the scenarios and characterize the characters for the computer tool eight specialists, professionals from the chemical dependency field (PG3), recommended situations, places, objects, signs, or cues thought to trigger craving.

\subsection{Validation of the psychophysiological signals}

As the relationship between physiological measurements and their psychologic meaning is complex [38,39]. We established the psychophysiological validation in laboratory, relating the variation of BMP and RR with the changes in body posture of 30 volunteers [40].

Two physiological signals, BMP and RR, were used as indicators of anxiety following the model two-to-one of the physiology mapping on computer systems [38] and [39].

Respiration rate and tonic heart rate produces continuous information over the duration of the stimulus [41]. In our research stressors, presented in the sceneries, are only one minute long with intervals of one minute in between. The tonic heart rate and respiration signals produce contiguous information over the duration of the stimulus. The selection of the scenery was accomplished by the program used in our research and was only based on the variation of the rate (frequency) of the physiological signals and not on the variation of its amplitude. To measure the heart rate we used a Polar M32 (Polar Electro, Kempele, Finland). The respiratory frequency was measured using a device developed by the Brazilian company Engecer. It was used to monitor the breathing rate of newborns in intensive care using a temperature sensor to monitor the air exhaled through the nose.

Initially, the PG1 specialists evaluated the VG group measuring heart rate and respiratory rate while they were in a normal state (basal levels). The volunteers have been submitted to 'stress' situations that could favor the change of their emotional state to anxious. Therefore, it was requested that the VG volunteers access the commercial computer game: A-BLAST. In this free available game, the user drives a spacecraft vehicle aiming to destroy the surrounding aliens present at the scenario. Aiming to influence the increment of anxiety's levels, the mouse sensibility was altered 
without the perception of the user. Similar techniques were used by several authors to cause anxiety [42-44].

While playing A-BLAST, the VG volunteers were monitored by the PG1 specialists to verify the user's emotional state together with the acquisition of heart and respiratory rate. These therapists used the BAI method, developed by [45] translated and adapted for the Brazilian population to perform the diagnosis.

The cut-off threshold (COT) for the emotional state was calculated according to Eqs. (1)-(3). In these equations $\bar{x}$ and $s$ are respectively the samples mean and its standard deviation for each physiological signal during both basal and anxious states. The COT between normal and anxious state was obtained by subtracting the normalized samples mean by its respective standard deviation.

$\bar{x}=\frac{\sum_{i=1}^{n} x_{i}}{n}$

$s=\sqrt{\sum_{i=1}^{n} \frac{\left(x_{i}-\bar{x}\right)^{2}}{n-1}}$

$\mathrm{COT}=\bar{x}-s$

$x_{i}$ and $n$ are the $i$ th sample element and the total number of samples.

The COT for heart rate and respiratory rate were applied to the game while the users were playing and the emotional state determined as the average of the therapeutic diagnostics.

During the virtual exposure, the heart rate and respiratory rate of the chemically dependent individuals were acquired and processed to be classified as a normal or anxious state. Then, the scenes were automatically changed depending on the captured physiological signals. Coping and escaping were the two possibilities that the CT can choose for each given situation.

\subsection{Test protocol for chemically dependent individuals CDG}

Before the test with the chemically dependent individuals (CDG), the therapists (PG2) answered a questionnaire identifying the situations of risk presented in the CT that could lead the chemically dependent individual to relapse. The same questionnaire was also completed by the dependent before and after the CT test. In addition, this questionnaire was structured based on risk factors survey.

The questions presented are listed below:

1. If you receive a phone call from a friend that is a drug user, would it stimulate you to take drugs?

2. If you walk on places that used to be selling drugs areas, would you relapse by any chance?

3. If a colleague invites you to have drinks, would you be favored by taking drugs?

4. Family issues or situations where the family is absent, would it contribute to your relapse?

5. Would you relapse if you had the chance of going party or places that might have drugs?

6. A friendship that is a drug user and can offer it to you would trigger your wishes for having drugs?

The questionnaire and CT test were applied to each chemically dependent individual (CDG). The therapists of the dependents were present while performing the test. The test was conducted in a comfortable room that was part of a therapeutic community for chemically dependent individuals. This room held the test equipment, a support table for the equipment, and chairs for the dependent and therapist. Communication during the test was not recommended. Extra care was taken to avoid tests' interruptions including disturbance caused by equipment (air conditioning, audio,

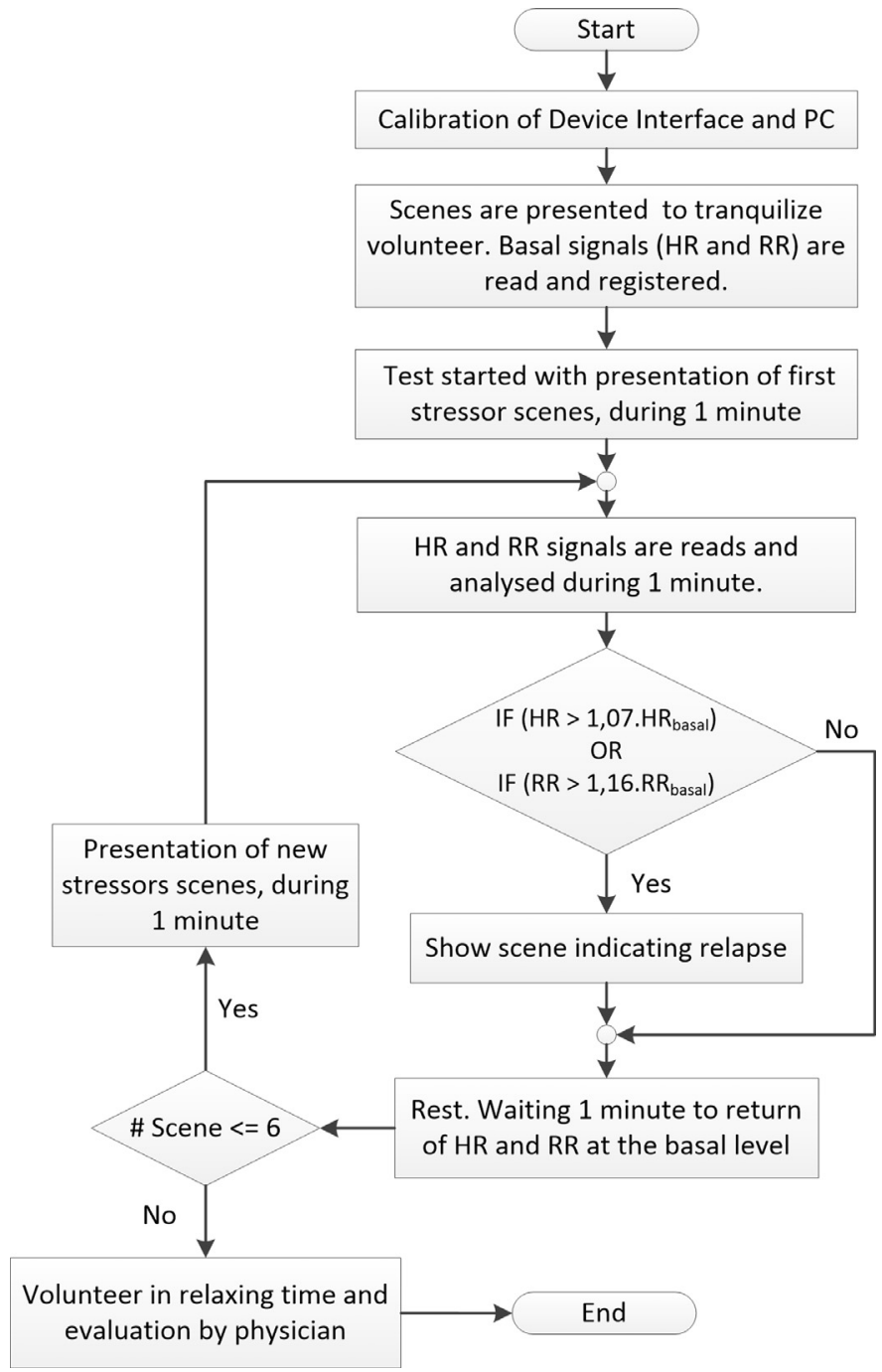

Fig. 1. Simplified flowchart of the system operation.

etc.) as well as people entering at the exam room. Regarding the sensors, the cardiac frequency meter was placed on the distal phalanx of the little finger and the respiratory rate (RR) sensor near the right nostril using a headset support. The chemically dependent individuals were informed that the outcome of each situation presented in the CT would correspond to their physiological state when facing the risk situations. It was emphasized that only their emotions were shown to influence the scenarios.

The test started with the volunteers watching a desired film selected by them where the basal levels from both physiological signals were simultaneously acquired. It was followed by the scene with the first stressor stimulus of the CT where heart rate and respiratory rate were measured during one minute and compared with the previously acquired baseline levels. The program automatically selected the following scenes depending on the identified COT. When the state was identified as anxious, the program changed the scene, showing the character using drugs. Otherwise, the plot proceeded. Following the program continued to trade with a landscape scene of a minute. The same timing was used after each other stressful scene. Fig. 1 shows the flow chart of the program. After this test a relaxation session monitored by the therapists took place followed by the completion of the questionnaire. 


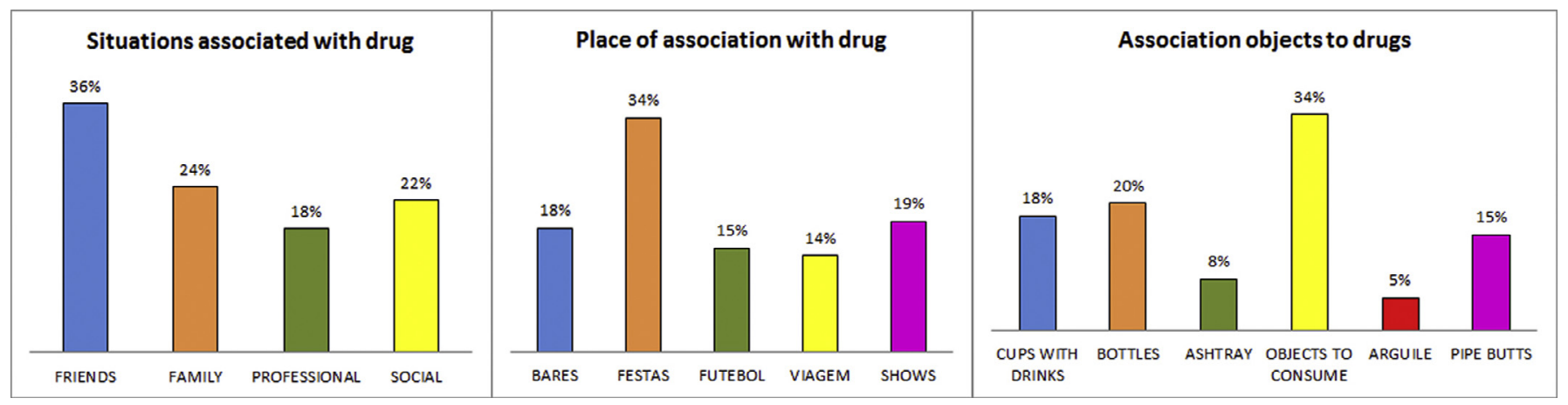

Fig. 2. Graphical representation of the answers provided by professionals from the PG about objects, places, and risk situations that can lead to relapse.

Table 1

Parameters suggested by Landis and Koch [46] to interpret Kappa statistics.

\begin{tabular}{ll}
\hline VALUES OF KAPPA - INTERPRETATION \\
\hline$<0.00$ & Poor \\
$0.00-0.20$ & Slight \\
$0.21-0.40$ & Fair \\
$0.41-0.60$ & Moderate \\
$0.61-0.80$ & Substantial \\
$0.81-1.00$ & Almost Perfect \\
\hline
\end{tabular}

\subsection{Data analysis}

To verify and confirm agreements and divergences between the results, Cohen's Kappa analysis was used. The data was interpreted according to the parameters suggested by Landis and Koch [46] (see Table 1).

The formulas for Cohen's Kappa index are as follows:

$K=\frac{p_{0}-p_{e}}{1-p_{e}}$

$s e_{(K)}=\sqrt{\frac{1}{N\left(1-p_{e}\right)^{2}} \times\left\{p_{e}+p_{e}{ }^{2}-\sum_{i=1}^{c}\left[a_{i} b_{i}\left(a_{i}+b_{i}\right)\right]\right\}} ;$

$Z=\frac{K}{s e_{(K)}}$

$p($ valor $)=1-\phi(Z)$

where

$\mathrm{p}_{\mathrm{o}}=$ chance of observed agreement;

$\mathrm{p}_{\mathrm{e}}=$ chance-expected agreement;

D' Agostino test was applied to show that the heart rates and respiratory rates of the volunteers VG are parametric. ANOVA test was also implemented to verify significant differences between the physiological signals at each emotional state of the volunteers VG.

\section{Implementation of the CT}

\subsection{Plot and storyboard}

To develop a CT that provides immersion in the virtual scenarios, risk situations were simulated using models, objects, threedimensional characters, videos, and audio features. The information provided by the eight professionals from the PG3 was used to create the scenarios (please see Fig. 2).

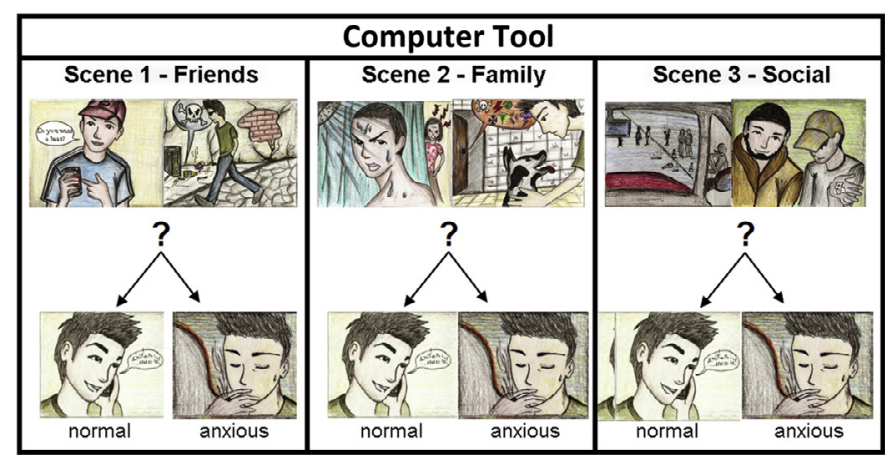

Fig. 3. Illustration of the composition of the CT.

To create and develop the game's narrative, the authors made use of situations associated with friends, family, and parties identified by these professionals (PG3). The objects identified by the chemically dependent individuals mostly related to the drug use were included in the scenarios. The main character performed in the first person (graphical perspective rendered from the viewpoint of the player character). Thus, the players were virtually translocated to the camera position, allowing the experience, visualization, and identification of their behaviors according to the character's reaction.

A plot with two different types of outcomes based on the player's emotional state was developed for each situation (Fig. 3). If the player's emotional state remained normal, the character remained in the game, but if the player became anxious, the character relapsed. The relapse was represented for approximately $30 \mathrm{~s}$. In this scene, the character under the effects of drugs showed symptoms such as psychomotor agitation and change in vision. The therapists were asked to monitor and provide emotional support to the chemically dependent. The next scenario with a different risk situation was presented $30 \mathrm{~s}$ later.

The CT portrays the character being invited by other chemically dependent colleague to an evening party. On the way to the friend's house, the character goes through places that can elicit memories related to drug use. If the physiological signals of the player demonstrate anxiety, the character relapses and uses drugs again. If these signals do not change significantly, the player arrives at the friend's house.

At the friend's house, the character plays with a dog while listening to an argument between the friend and his mother. The mother complains that her son is unemployed, questions his behaviors and friends, and suspects that he is stealing money and household objects. If the player demonstrates anxiety, the character relapses, but if the player has no physiological changes, the 


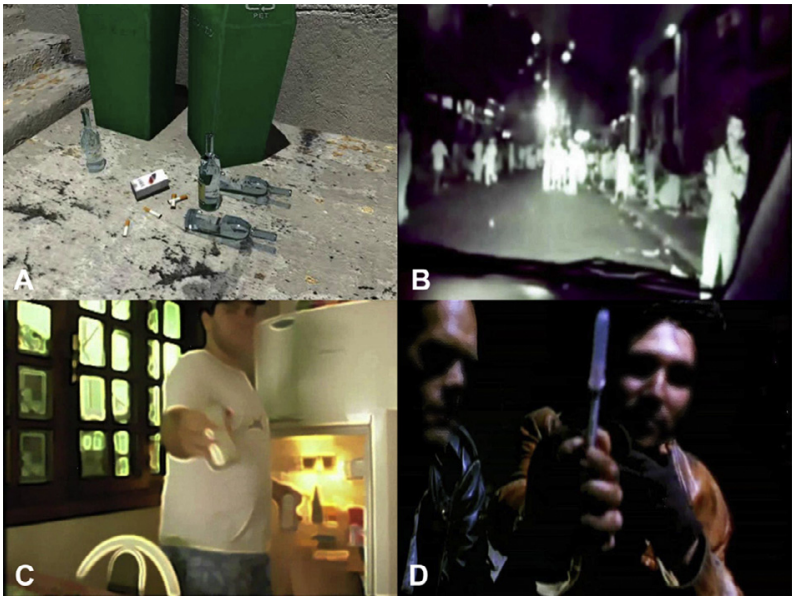

Fig. 4. Computer tool scenarios. (A) and (B) shows ways of drug consume. (C) Offering alcoholic drinks. (D) Offering drugs.

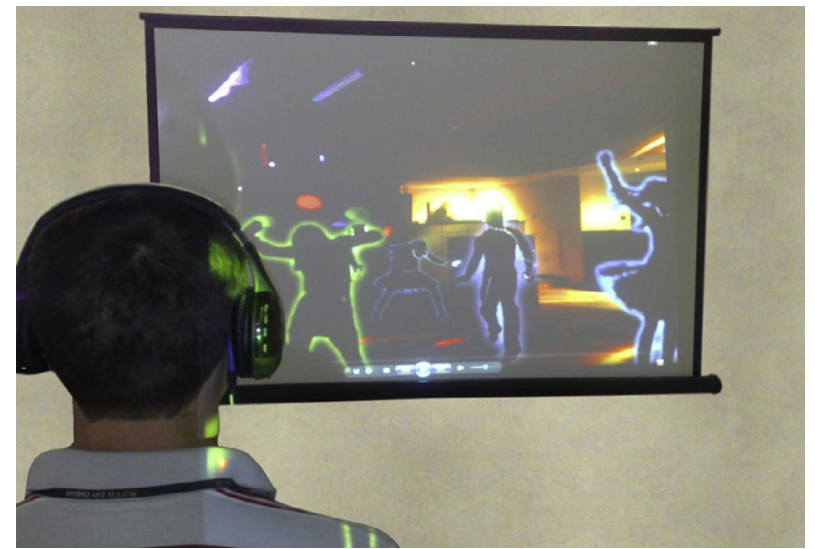

Fig. 5. A volunteer at the scenario of party during the test using the multimedia resources (projector, projection screen and wireless headset).

character continues playing with the dog and goes to the party with the friend.

On their way, the virtual characters encounter secondary characters using drugs. If the chemically dependent player demonstrates anxiety, the character gets out of the car and start making use of drugs, featuring a relapse. If the physiological signals do not change, the character arrives at the party.

At the party, the character is approached by two drug dealers who offer him drugs. If the player demonstrates anxiety, the character cannot refuse and returns to drug use. If no relevant physiological changes occur, the character dances until the end of the night.

\subsection{Flowchart of the CT plot}

The Autodesk ${ }^{\circledR}$ 3ds Max ${ }^{\circledR}$ software was chosen to develop the CT because it allows for polygon modelling and texturing, generation of three-dimensional digital animation, rendering of images and animations, and insertion of videos in the AVI format. Fig. 4 shows some of the scenarios developed.

For the CT test were used a multimedia projector with a projection screen $(1.80 \times 1.80 \mathrm{~m})$ and a wireless headset (Fig. 5).

Fig. 6 displays the flowchart of the CT plot.
Table 2

Average of the physiological signals collected from minute to minute during $10 \mathrm{~min}$ at each emotional state from the VG's group.

\begin{tabular}{|c|c|c|c|c|}
\hline \multicolumn{5}{|c|}{ Mean of the 10 min physiological signals ongoing stimulus } \\
\hline \multirow[t]{2}{*}{ Volunteers } & \multicolumn{2}{|c|}{ Heart rate } & \multicolumn{2}{|c|}{ Respiratory rate } \\
\hline & Anxious & $\overline{\text { Normal }}$ & Anxious & Normal \\
\hline 1 & 90.4 & 76.0 & 18.9 & 17.5 \\
\hline 2 & 87.7 & 84.9 & 22.3 & 14.8 \\
\hline 3 & 90.7 & 83.6 & 24.0 & 17.2 \\
\hline 4 & 78.0 & 69.1 & 21.7 & 14.7 \\
\hline 5 & 71.9 & 67.3 & 19.4 & 13.2 \\
\hline 6 & 84.3 & 78.3 & 20.9 & 17.1 \\
\hline 7 & 98.3 & 89.5 & 21.7 & 16.1 \\
\hline 8 & 88.6 & 75.0 & 21.1 & 15.9 \\
\hline 9 & 84.1 & 75.1 & 17.0 & 13.1 \\
\hline 10 & 81.1 & 74.8 & 20.0 & 16.6 \\
\hline 11 & 93.8 & 79.8 & 17.8 & 17.3 \\
\hline 12 & 86.9 & 78.7 & 20.6 & 16.6 \\
\hline 13 & 98.3 & 76.1 & 18.8 & 15.3 \\
\hline 14 & 87.9 & 78.4 & 23.6 & 18.0 \\
\hline 15 & 77.3 & 69.4 & 20.4 & 17.0 \\
\hline 16 & 79.9 & 65.5 & 19.3 & 14.5 \\
\hline 17 & 89.6 & 81.4 & 20.4 & 15.2 \\
\hline 18 & 82.6 & 71.9 & 18.0 & 15.0 \\
\hline 19 & 84.8 & 76.0 & 24.2 & 15.8 \\
\hline 20 & 74.5 & 71.2 & 23.0 & 16.7 \\
\hline 21 & 93.7 & 81.4 & 18.9 & 13.4 \\
\hline 22 & 90.3 & 81.9 & 16.8 & 14.5 \\
\hline 23 & 87.2 & 80.3 & 18.0 & 16.0 \\
\hline 24 & 89.2 & 80.0 & 18.0 & 13.1 \\
\hline 25 & 107.6 & 85.1 & 22.0 & 18.7 \\
\hline 26 & 83.0 & 73.6 & 19.8 & 14.3 \\
\hline 27 & 90.6 & 80.3 & 22.7 & 15.3 \\
\hline 28 & 83.7 & 77.1 & 24.5 & 16.5 \\
\hline 29 & 88.3 & 76.1 & 18.8 & 15.3 \\
\hline 30 & 95.6 & 86.3 & 18.8 & 17.4 \\
\hline Mean & 87.3 & 77.5 & 20.4 & 15.7 \\
\hline Standard deviation & 7.5 & 5.7 & 2.2 & 1.5 \\
\hline
\end{tabular}

\section{Results}

4.1. Determining the emotional state thresholds for the non-drugs users

The physiological signals were collected every minute from the VG population. The signals' average was calculated for each individual and emotional state (normal vs. anxious).

The normalized values of the mean heart and respiratory rates were calculated for both anxious and normal states (Table 2). These values were normalized based on the individual basal value of each volunteer VG.

The statistical significance from the heart rate and frequency rate for both normal and anxious states was $(p<0.01)$ highlighting a clear distinction between the different emotional states.

The cut-off threshold (COT) for the anxious state was obtained through Eq. (3). A volunteer was considered to be anxious if the heart rate $(\Delta \mathrm{HR})$ or respiratory rate $(\triangle \mathrm{RR})$ is at least $7 \%$ and $16 \%$ above the basal levels respectively (Table 3 and Fig. 7).

\subsection{Evaluation of de $C T$}

\subsubsection{Quantitative analysis}

The professionals (PG2) and the fifty volunteers (CDG), whose demographic data is represented in Table 4, filled in the questionnaires.

The analysis of the questionnaire responses revealed that before using CT, the majority of the volunteers reported they would have a $4 \%$ to $30 \%$ chance of relapse, varying with the different risk 


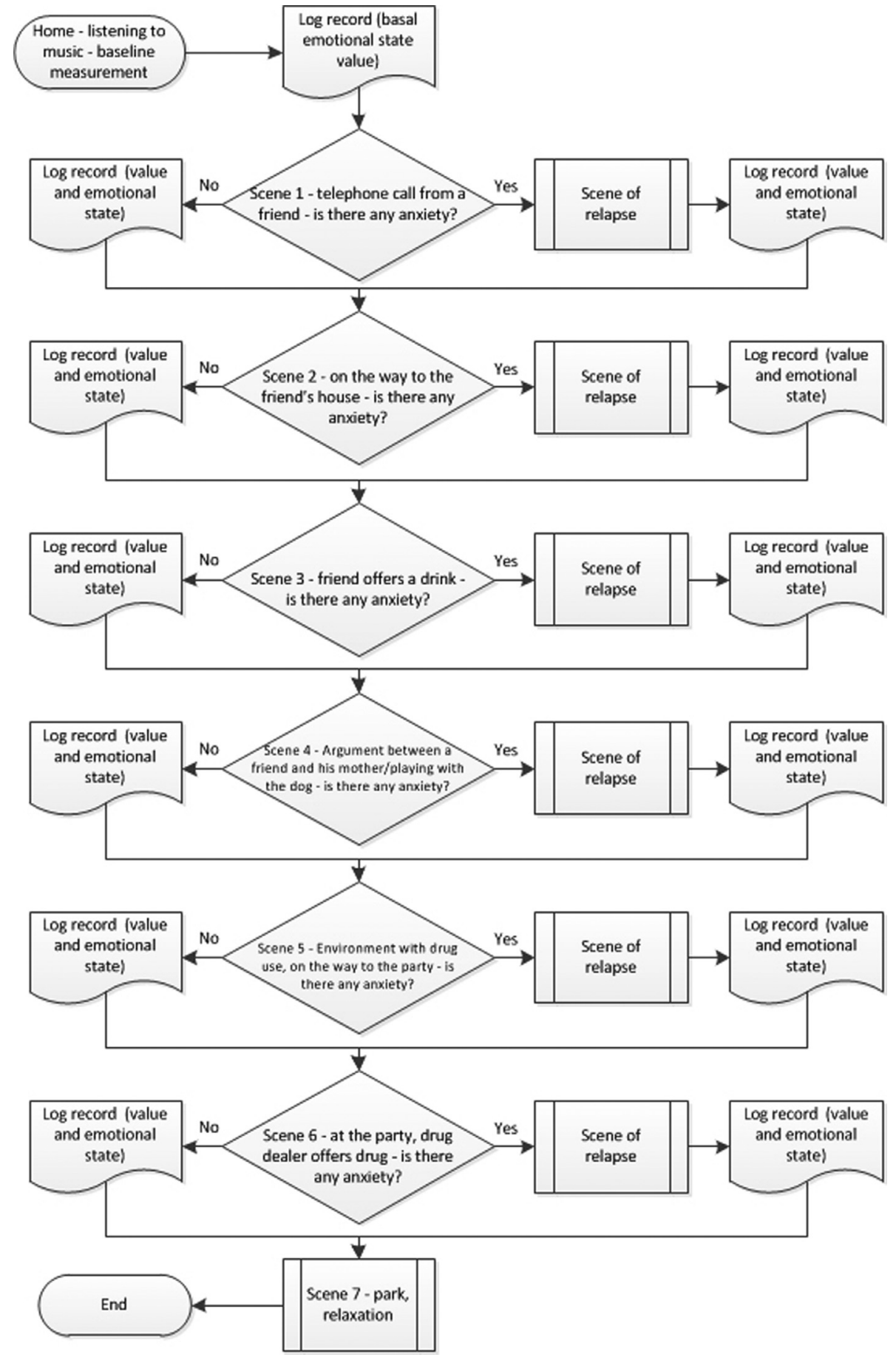

Fig. 6. Flowchart of the CT.

situations. For the therapists, the probabilities ranged from $42 \%$ to $98 \%$.

The disparity between the means of the volunteers' responses before CT and the means of the professionals' diagnoses for each risk situation is depicted in Fig. 8.

During the CT test, the chemically dependent individuals presented virtual relapse rates similar to the rates predicted by the therapists.

The virtual relapses helped raise awareness in these volunteers, as demonstrated by their responses after the test. This shows that the chemically dependent individuals significantly changed their opinions, and their responses after the test were similar to the professionals' predictions.

The graph displayed in Fig. 8 demonstrates that volunteer' responses to the questionnaire differed greatly before the CT test from the all other predictions. However, after the test they were very similar to the professionals' diagnoses and concurred with their responses in the CT. The vulnerability of the chemically dependent individuals was demonstrated by the high relapse rate. Only the risk situation "contact the drug's user friend" presented a relapse rate below $50 \%$. The risk situation "offering drugs" triggered cravings the most, according to all volunteers. 
Table 3

The normalized mean values of the physiological signals (and standard deviation) for anxious emotional state of the volunteers of group VG playing the game A-BLAST. The values were normalized based on the individual basal value of each volunteer VG.

\begin{tabular}{lll}
\hline \multicolumn{3}{l}{ Normalized mean values of the physiological signals } \\
\hline Volunteers & Heart rate & Respiratory rate \\
\hline 1 & 1.19 & 1.08 \\
2 & 1.03 & 1.51 \\
3 & 1.08 & 1.40 \\
4 & 1.13 & 1.48 \\
5 & 1.07 & 1.47 \\
6 & 1.08 & 1.22 \\
7 & 1.10 & 1.35 \\
8 & 1.18 & 1.33 \\
9 & 1.12 & 1.30 \\
10 & 1.08 & 1.20 \\
11 & 1.18 & 1.03 \\
12 & 1.10 & 1.24 \\
13 & 1.29 & 1.23 \\
14 & 1.12 & 1.31 \\
15 & 1.11 & 1.20 \\
16 & 1.22 & 1.33 \\
17 & 1.10 & 1.34 \\
18 & 1.15 & 1.20 \\
19 & 1.12 & 1.53 \\
20 & 1.05 & 1.38 \\
21 & 1.15 & 1.41 \\
22 & 1.10 & 1.16 \\
23 & 1.09 & 1.13 \\
24 & 1.11 & 1.37 \\
25 & 1.26 & 1.18 \\
26 & 1.13 & 1.38 \\
27 & 1.13 & 1.48 \\
28 & 1.09 & 1.48 \\
30 & 1.16 & 1.23 \\
Mean & 1.11 & 1.08 \\
Standard deviation & $\mathbf{0 . 0 6}$ & $\mathbf{0 . 1 4}$ \\
\hline
\end{tabular}

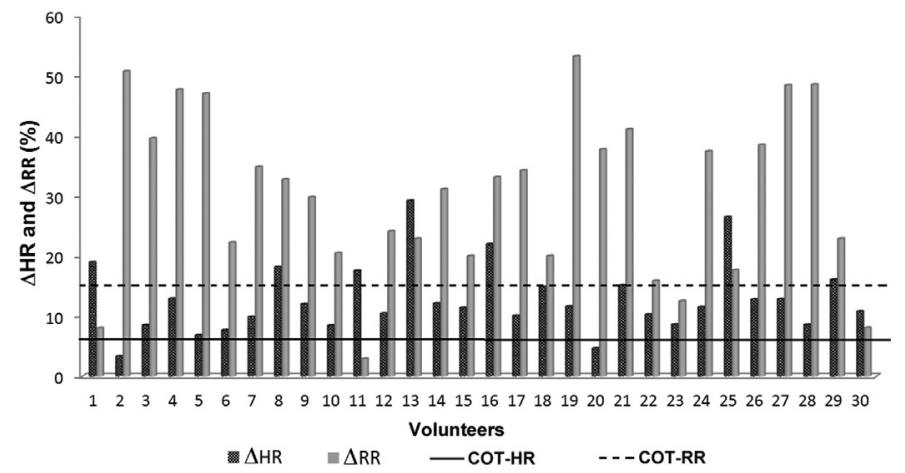

Fig. 7. $\Delta H R$ and $\Delta R R$ of 30 volunteers (VG). The COT-HR (solid) and COT-RR (dotted) lines indicate the percent variation of $H R(\Delta H R(\%))$ and the percent variation of $R R(\Delta R R(\%))$ from which the volunteer is considered anxious . All volunteers exceeded the COT point in at least one of the signs (HR or RR).

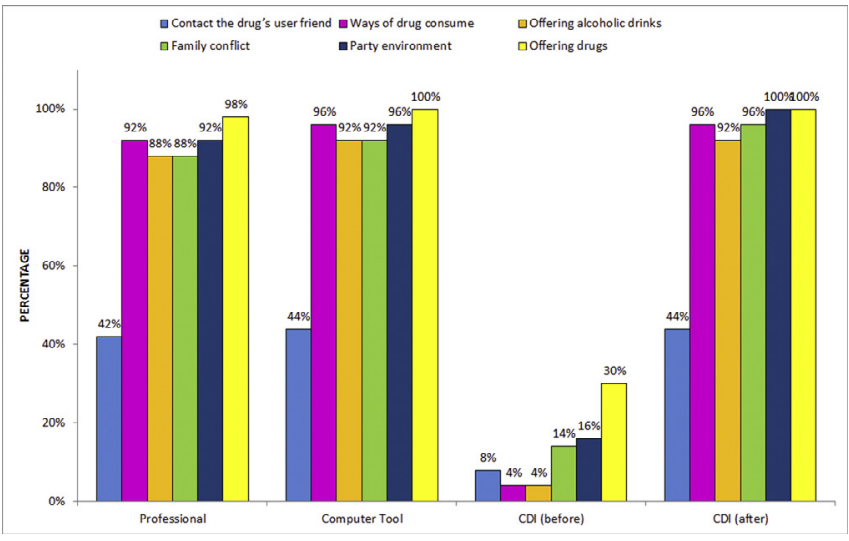

Fig. 8. Comparison of the relapse predictions of the addicts before and after the test, with the therapist's predictions as well as virtual relapses in the CT for each risk situation (\%).

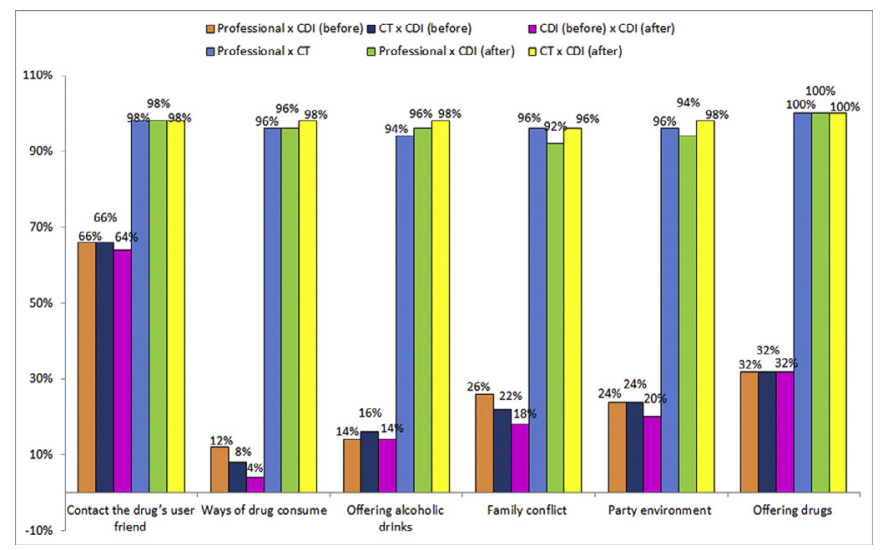

Fig. 9. Graphical representation of the agreement observed for all evaluators in each risk situation.

Table 5 presents the Kappa indexes and their respective ranks for the comparisons between evaluators in each risk situation.

Table 6 shows the Kappa index for all of the situations. The correlation between the responses of the chemically dependent individuals before and after the test had a Kappa index of 0.043 ("Slight"). The correlation between the professionals and the chemically dependent individuals (after the test) had a Kappa index of 0.710 ("Substantial"), indicating that the volunteers were more aware of possible relapses.

\subsubsection{Qualitative evaluation}

\section{(a) Assessment of the CT by the therapists}

The therapists (PG2) assessed the level of realism of the anxiety stimuli, i.e., the risk situations presented in the CT. All of therapists concluded that the scenarios are a good reproduction of the reality experienced by the vast majority of chemically dependent individuals. Regarding content and immersion, these professionals believed that the elements used in

Table 4

Calculated thresholds cut-off values for categorization of the anxious emotional state according to the physiological heart and respiratory rates.

\begin{tabular}{llll}
\hline \multicolumn{4}{l}{ Identification of the anxious cut-off threshold (COT) values for both heart and respiratory } \\
\hline Physiological signal & Emotional state & $\bar{x}-s$ & COT \\
\hline Heart rate & Anxious & $1.13-0.06=1.07$ & $\geq 7 \%$ \\
Respiratory & Anxious & $1.30-0.14=1.16$ & $\geq 16 \%$ \\
\hline
\end{tabular}


Table 5

Demographic characteristics of the fifty volunteers (CDG).

\begin{tabular}{|c|c|c|c|c|c|c|c|}
\hline $\begin{array}{l}\text { Educational } \\
\text { grade }\end{array}$ & Illiterate & $\begin{array}{l}\text { Elementary } \\
\text { grade } \\
\text { incomplete }\end{array}$ & $\begin{array}{l}\text { Elementary } \\
\text { grade complete }\end{array}$ & $\begin{array}{l}\text { High school } \\
\text { incomplete }\end{array}$ & $\begin{array}{l}\text { High school } \\
\text { complete }\end{array}$ & $\begin{array}{l}\text { Undergraduate } \\
\text { incomplete }\end{array}$ & $\begin{array}{l}\text { Undergraduate } \\
\text { complete }\end{array}$ \\
\hline & $4 \%$ & $18 \%$ & $32 \%$ & $6 \%$ & $30 \%$ & $4 \%$ & $6 \%$ \\
\hline \multirow[t]{2}{*}{ Religion } & No religion & Catholics & Evangelicals & Others & & & \\
\hline & $10 \%$ & $48 \%$ & $40 \%$ & $2 \%$ & & & \\
\hline \multirow[t]{2}{*}{ Marital status } & Singles & Married & Divorced & & & & \\
\hline & $40 \%$ & $36 \%$ & $24 \%$ & & & & \\
\hline \multirow[t]{2}{*}{ Children } & Yes & No & & & & & \\
\hline & $80 \%$ & $20 \%$ & & & & & \\
\hline \multirow[t]{2}{*}{ Housing } & With family & Alone & Own & Leased & Borrowed & & \\
\hline & $72 \%$ & $28 \%$ & $56 \%$ & $26 \%$ & $18 \%$ & & \\
\hline \multirow{2}{*}{$\begin{array}{l}\text { Financial } \\
\text { assistance }\end{array}$} & Yes & Not & & & & & \\
\hline & $66 \%$ & $34 \%$ & & & & & \\
\hline \multirow{2}{*}{$\begin{array}{l}\text { Family } \\
\text { income }\end{array}$} & Up to $1 \mathrm{MS}$ & 1 to $2 \mathrm{MS}$ & 2 to $4 \mathrm{MS}$ & 4 or more MS & & & \\
\hline & $36 \%$ & $38 \%$ & $18 \%$ & $8 \%$ & & & \\
\hline \multirow{2}{*}{$\begin{array}{l}\text { Contribute to } \\
\text { family income }\end{array}$} & Yes & Not & & & & & \\
\hline & $78 \%$ & $22 \%$ & & & & & \\
\hline \multirow[t]{2}{*}{$\begin{array}{l}\text { Option for } \\
\text { treatment }\end{array}$} & Own decision & Family decision & $\begin{array}{l}\text { Medical } \\
\text { decision }\end{array}$ & & & & \\
\hline & $72 \%$ & $16 \%$ & $12 \%$ & & & & \\
\hline \multirow[t]{2}{*}{$\begin{array}{l}\text { Type } \\
\text { addiction }{ }^{* *}\end{array}$} & Alcohol & Tobacco & $\begin{array}{l}\text { Cocaine and } \\
\text { Derivatives }\end{array}$ & Marijuana & & & \\
\hline & $72 \%$ & $56 \%$ & $70 \%$ & $32 \%$ & & & \\
\hline
\end{tabular}

* Family income was parameterized in minimum salary (MS) of Brazil. One MS equal to US\$278.00 in August 2016.

${ }^{* *}$ In these responses, the patient could answer one or more substances, cross dependence.

Table 6

Kappa indexes among evaluators for each risk situation present in the questionnaires.

\begin{tabular}{|c|c|c|c|c|c|c|}
\hline & $\begin{array}{l}\text { Contact the drug's } \\
\text { user friend }\end{array}$ & $\begin{array}{l}\text { Ways of drug } \\
\text { consume }\end{array}$ & $\begin{array}{l}\text { Offering alcoholic } \\
\text { drinks }\end{array}$ & Family conflict & Party environment & Offering drugs \\
\hline Professional $\times \mathrm{CT}$ & 0.96 & 0.65 & 0.73 & 0.47 & 0.65 & 1.00 \\
\hline $\begin{array}{l}\text { Professional } \times \text { Chemical } \\
\text { Dependent (before) }\end{array}$ & 0.214 & 0.007 & 0.006 & 0.043 & 0.03 & 0.017 \\
\hline $\begin{array}{l}\text { Professional } \times \text { Chemical } \\
\text { Dependent }(\text { after })\end{array}$ & 0.95 & 0.648 & 0.779 & 0.468 & 0.38 & 1.00 \\
\hline $\begin{array}{l}\text { Chemical Dependent } \\
\text { (before) } \times \text { Chemical } \\
\text { Dependent (after) }\end{array}$ & 0.24 & 0.001 & 0.009 & 0.013 & 0.016 & 0.017 \\
\hline $\begin{array}{l}\mathrm{CT} \times \text { Chemical Dependent } \\
\text { (before) }\end{array}$ & 0.214 & 0.003 & 0.011 & 0.028 & 0.036 & 0.017 \\
\hline $\begin{array}{l}\mathrm{CT} \times \text { Chemical Dependent } \\
\text { (after) }\end{array}$ & 0.96 & 0.79 & 0.88 & 0.68 & 0.79 & 1.00 \\
\hline
\end{tabular}

Table 7

Mean value of the Kappa indexes and interpretation between evaluators.

\begin{tabular}{lll}
\hline Professional $\times$ chemical dependent (before) & 0.053 & Slight \\
CT $\times$ chemical dependent (before) & 0.052 & Slight \\
Chemical Dependent (before) $\times$ chemical dependent (after) & 0.043 & Slight \\
Professional $\times$ CT & 0.890 & Almost perfect \\
Professional $\times$ chemical dependent (after) & 0.710 & Substantial \\
CT $\times$ chemical dependent (after) & 0.850 & Almost perfect \\
\hline
\end{tabular}

the graphical interface and the audio features favored immersion in the CT, which aids in the incorporation of information and retention of the contents.

The main item highlighted by the PG2 was the feedback given by the relapse scenes, providing an immediate response to the emotions of the chemically dependent individuals. Because an emphatic verbalization of the possibility of relapse was not necessary, the impasse between chemically dependent individual and therapist was prevented. The elaboration of a library of virtual scenarios to encompass the individual characteristics of the volunteers was suggested by therapists to improve the tool.

(b) Assessment of the CT by the chemically dependent individuals

After being tested, the 50 volunteers (CDG) were also asked about the content, realism, and immersion in the CT. All of the volunteers found the content close to reality, presenting the main difficulties that they experience in daily life. Many justified their answers with comments about their life expe- 
riences and described scenarios that they experienced. Others were surprised by the recognition of their difficulties in dealing with the situations presented in the CT. Regarding the realism, the virtual scenarios were considered reliable by the volunteers. Some volunteers suggested the inclusion of other scenarios with more risk situations, other places of drug consumption, more stereotypes of drug users, and additional musical styles. As for immersion, the majority felt that the scenarios, the character's actions and the sequence of the story were engaging, thereby allowing them to identify with the situations. The volunteers stressed that there were no concerns about the sensors, external interferences, or other assessments. Additionally, there were no complaints of discomfort caused by the sensors. The volunteers were interested in the technique used for cue reactivity.

\section{Discussion}

The proposed study has as peculiarity the development of CT contributing to the user immersion. One of the crucial characteristics of this virtual tool is the use of machine language codes that boost the apps performance. In addition, the proposed CT has also the advantage to be oriented to objects, where each element's phase interface can be associated to a series of events.

The 3ds Max tool used to implement CT has several polygon modeling modes. In addition, plugins for modifiers can be used if necessary. The 3ds Max software allows high-quality rendering with lights, shadows, and transparencies. With this rendering, realistic images were generated, simulating realistic environments and internal/external scenarios, providing virtual emotions that are often more effective than emotions staged by actors [47].

The files generated by 3ds Max have the native extension .MAX, but they are compatible with several three-dimensional modeling software programs, allowing for the conversion of files with the extensions .DS, .DXF, .DWG, and others. This software is widely used in desktop, multi-tier, and client-server applications, and it is compatible with most databases. One of the main features of this development environment is the generation of codes in machine language that accelerate the execution of the applications. The other is the orientation to events, where each element of an application's interface can capture and associate actions to a series of events.

The change in the signal from the normal state of each individual, collected for $1 \mathrm{~min}$, provided satisfactory and very simple application responses to command the sceneries presented with the computer tool in real time. The respiratory frequency meter (RR) was a device used to monitor the breathing of premature babies in intensive care and provided a reliable assessment.

Therapists and chemically dependent individuals highlighted the realism of the scenarios, the characters, and their speech and emphasized the importance of certain sounds, such as the noise of a can of beer being opened. These elements conveyed the feeling of being in places and environments visited in real life.

Other researchers [26] also used these types of sound resources in a VE that was developed to detect crack cocaine and cocaine cravings among users. Situations and places, such as parties and bars, as well as objects, such as bottles and glasses, rolled up papers, and lighters, were also found to be directly associated with craving and consequently with the drug [7,30]. These same items were considered risk factors in college environments by researchers [8], who emphasized the high number of students consuming psychoactive substances. The authors also reported that drug addiction is a gradual process; therefore, attention and assistance through specific interventions with the implementation of awareness programs are necessary and important.

The responses to the questionnaires administered before the test with the CT demonstrated that the 50 chemically dependent individuals (CDG) who participated in this study estimated that they had, on average, a $12.6 \%$ probability of relapse, while the professionals (PG1) who were monitoring them predicted an $83.3 \%$ probability of relapse. These data illustrate a considerable divergence of opinion between patient and therapist. This situation describes one factor that increases the possibility of relapses in clinical practice, showing that the patient has no mechanisms or training to face the risk situations. However, the Kappa index between the professional's predictions and the responses in the CT indicates strong agreement. Importantly, the effectiveness of the CT and cue reactivity was demonstrated by the revised opinions of the chemically dependent individuals after undergoing the test.

This effectiveness was also shown by authors [30] using a VE system that aimed to increase craving in cannabis-dependent individuals when exposed to visual, olfactory, and auditory stimuli. These authors demonstrated that the VEs are similar to exposure therapies. Other authors [48] indicate that the advantage of VEs over traditional exposure therapy is the ability to provide a sense of presence to the individual, which is defined by [49] and [50] as the "feeling of being in a world that exists outside the self". Virtual exposure allows the user to experience risk situations that may lead to relapse in real life, which facilitates the therapist's goal of raising awareness of these situations.

VE has also been successfully employed in therapies that address acute pain [51-53] and obsessive-compulsive disorder [54]. Additionally, VE has been used for post-stroke rehabilitation [5557], to assess reactivity to addiction [20,58], and to assess reactivity to stress [59].

Several authors have demonstrated the effectiveness of VE in support of addiction treatment [28]. These authors used VE therapy to reduce the craving for alcohol in alcohol-dependent patients. The results suggest that this therapy may be useful for treatment and can furthermore serve as an assessment tool to identify high-risk patients.

Several authors [60-64] have employed VE to treat anxiety disorders and general phobias and have reported their users' acceptance of this tool. Others [29] also showed that VE is well accepted by patients undergoing treatment for alcoholism and offers significant clinical advantages over other methods.

Other researchers [20] used VE to measure alcohol cravings. The volunteers reported high levels of engagement with the scenarios, considering them realistic and compelling. These authors state that despite these promising results, there are limitations that should be addressed in future studies, including the incorporation of an objective measure that can identify physiological changes caused by craving, such as heart rate, skin conductance, and brain imaging.

To evaluate the ability of the VE to elicit craving, researchers [26] verified physiological changes by measuring heart rate and galvanic response of the skin. Others [27] used a freely available gaming platform (Second Life) to elicit craving for methamphetamines and measured heart rate to assess physiological reactivity. In the present study, CT was also developed to elicit craving, and changes in physiological signals were measured. However, these signals were used to direct the actions of the environment and to provide objective feedback to the chemically dependent individuals, according to their emotions.

Physiological variables such as skin surface temperature (ST), galvanic skin response (GSR) and heart rate (HR) were widely used as indicators of emotional changes $[65,66]$. However, according to the ranking published [36], the two most relevant physiological signals for stress detection are: HRV (Heart Rate Variability) and GSR. Various researchers obtained anxiety classification levels exceeding 80\% using GSR [67-72]. Other recent research considers the HRV (Heart Rate Variability) as a sensitive indicator of stress $[35,73,74]$ and obtained stress detection rates close to $90 \%$, but requires signal processing. However, these scientific studies were not 
intended to identify the acute stress caused by short-term stressors. Several studies $[36,75,76]$ evaluated the tonic heart rate response to environmental stressors. The authors aimed to identify the occurrence of momentary stimulus that causes acute stress in the individual from the changes to their basal physiological parameters. Since these parameters returned to the initial state after remove the stressors, these methods do not identify long-term stress.

In our research, stressors are presented in sceneries with total duration of one minute and intervals of one minute justifying the choice of physiological signals responsive during this stimulation. We choose the BPM and RR signals that have momentary response to the stressor.

We used GSR and temperature variations in a pilot study, but did not obtain good results. This was probably due to the short duration (maximum one minute) of the stressing scenery used in our research. To permit the return of the physiological signals to their basal state, the sceneries with stimuli are alternated with sceneries without stress during one minute. Also the interface used to control our sceneries is sensitive to occurrence of the signal and not to its amplitude. Since with GSR the electrodermal response increases linearly when the stimuli increase, this signal is not suitable for the CT we used.

Considering the ease of reading and the wide commercial availability of HR and respiratory rate (RR) equipments, these signals are used in our research. They do not provide as accurate classification levels of anxiety as HRV, but provide the therapist with an easy tool to use in rehabilitation clinics giving a more effective prediction of vulnerability of relapse.

\section{Conclusion}

Chemical dependency is a problem that affects people of all social classes and requires specialized treatment. One of the greatest barriers to remission of individuals in drug treatment is anxiety. This feeling is present in normal human development, in response to changes, and in response to new and unique experiences. For chemically dependent individuals, anxiety is a warning signal that allows them to be aware of an imminent risk and, with their therapists, to develop strategies for addressing risk situations.

The physiological signals collected in the present study were measured, and this objectivity allowed the therapist, and most importantly the patients, to be aware of and identify their anxiety in risk situations. This physiological cue reactivity indicates worries and anxieties through changes in physiological signals. Cue reactivity discourages arguments regarding diagnosis because is based on objective data.

Therefore, this study presents a supporting tool that can be used for marijuana and cocaine dependent individuals for identification and awareness of their anxiety in risk situations that may lead them to relapse.

Importantly, this CT is not meant to replace any treatment step but rather to be a tool for enhancing the chemically dependent individuals' awareness. The final diagnosis of chemical dependence should not be given based on the information generated by the device, and the therapist should monitor and evaluate all of the processes to identify the addiction and possible consequences of substance abuse.

\section{Conflict of interest}

There is no conflict of interest between the authors.

\section{Acknowledgments}

MLS, AFF, HJQO, HM and TAS gratefully acknowledge financial support from the FAEP - Foundation for Support to Education and
Research of University of Mogi das Cruzes. MLS acknowledge research grant support from CAPES - Coordination for the Improvement of Higher Education Personnel.

\section{References}

[1] L. Karila, D. Gorelick, A. Weinstein, F. Noble, A. Benyamina, S. Coscas, et al. New treatments for cocaine dependence: a focused review, Int. J. Neuropsychopharmacol 11 (3) (2008) 425-438.

[2] GREA, Alcohol and drugs interdisciplinary group, http://www.neurociencias. org.br/pt/528/dependencia-quimica accessed 05.03.09.

[3] M. Ising, S. Lucae, E.B. Binder, T. Bettecken, M. Uhr, S. Ripke, et al., A genomewide association study points to multiple loci that predict antidepressant drug treatment outcome in depression, Arch. Gen. Psychiatry 66 (9) (2009) 966-975.

[4] J.M. Hennings, T. Owashi, E.B. Binder, S. Horstmann, A. Menke, S. Kloiber, et al. Clinical characteristics and treatment outcome in a representative sample of depressed inpatients: findings from the Munich antidepressant response signature (MARS) project, J. Psychiatr. Res. 43 (3) (2009) 215-229.

[5] A.J. Rush, M.H. Trivedi, S.R. Wisniewski, A.A. Nierenberg, J.W. Stewart, D. Warden, et al., Acute and longer-term outcomes in depressed outpatients requiring one or several treatment steps: a STAR*D report, Am. J. Psychiatry 163 (11) (2006) 1905-1917.

[6] APA, American psychiatric association. DSM IV, http://www.psych.org/practice/ dsm accessed 10.04.12.

[7] J.H. Lee, H. Kwon, J. Choi, B. Yang, Cue-exposure therapy to decrease alcohol craving in virtual environment, Cyberpsychol. Behav. 10 (5) (2007) 617-623.

[8] M.L. Silva, N.M.R. Santos, V. Barnabe, V.E. Valenti, Risk factors that may signify a propensity to the use of drugs in students at a public university, J. Hum. Growth Dev. 23 (3) (2013) 346-351.

[9] Y. Ogai, A. Haraguchi, A. Kondo, Y. Ishibashi, M. Umeno, H. Kikumoto, et al., Development and validation of the stimulant relapse risk scale for drug abusers in Japan, Drug Alcohol Depend. 88 (2007) 174-181.

[10] D.S. Harris, V.I. Reus, O.M. Wolkowitz, J.E. Mendelson, R.T. Jones, Repeated psychological stress testing in stimulant-dependent patients, Prog. Neuropsychopharmacol Biol. Psychiatry 29 (5) (2005) 669-677.

[11] M.O. Bonn-Miller, R.H. Moos, Marijuana discontinuation, anxiety symptoms, and relapse to marijuana, Addict. Behav. 34 (9) (2009) 782-785

[12] M. Arendt, R. Rosenberg, L. Foldager, G. Perto, P. Munk-Jorgensen, Psychopathology among cannabis-dependent treatment seekers and association with later substance abuse treatment, J. Subst. Abuse Treat. 32 (2007) 113-119.

[13] R Sinha, How does stress increase risk of drug abuse and relapse? Psychopharmacology 158 (4) (2001) 343-359.

[14] G.R. Breese, K. Chu, C.V. Dayas, D. Funk, D.J. Knapp, G.F. Koob, et al., Stress enhancement of craving during sobriety: a risk for relapse, Alcohol Clin. Exp. Res. 29 (2) (2005) 185-195.

[15] H.C. Fox, M. Talih, R. Malison, G.M. Anderson, M.J. Kreek, R. Sinha, Frequency of recent cocaine and alcohol use affects drug craving and associated responses to stress and drug-related cues, Psychoneuroendocrinology 30 (9) (2005) 880-891.

[16] N.L. Cooney, M.D. Litt, P.A. Morce, L.O. Bauer, L. Gaupp, Alcohol cue reactivity, negative-mood reactivity, and relapse in treated alcoholic men, J. Abnorm. Psychol. 106 (2) (1997) 243-250.

[17] S. Moylan, K. Gustavson, E. Karevold, S. Øverland, F.N. Jacka, J.A. Pasco, et al., The Impact of smoking in adolescence on early adult anxiety symptoms and the relationship between infant vulnerability factors for anxiety and early adult anxiety symptoms: the TOPP study, PLoS One 8 (5) (2013) e63252.

[18] D. Longshore, C. Teruya, Treatment motivation in drug users: a theory-based analysis, Drug Alcohol Depend. 81 (2006) 179-188.

[19] B.C. Wallace, Psychological and environmental determinants of relapse in crack cocaine smokers, J. Subst. Abuse Treat. 6 (2) (1989) 95-106.

[20] P.S. Bordnick, H.L. Copp, A. Traylor, K.M. Graap, B.L. Carter, M. Ferrer, Assess ing reactivity to virtual reality alcohol based cues including olfactory stimuli, Addict. Behav. 33 (2008) 743-756.

[21] P.S. Bordnick, K.M. Graap, H.L. Copp, J. Brooks, M. Ferrer, Virtual reality cue reactivity assessment in cigarette smokers, Cyberpsychol. Behav. 8 (5) (2005) 487-492.

[22] J.H. Lee, J. Ku, K. Kim, B. Kim, I.Y. Kim, B.H. Yang, et al., Experimental application of virtual reality for nicotine craving through cue exposure, Cyberpsychol. Behav. 6 (3) (2004) 275-280.

[23] I.P. Pavlov, V.A. Gleb, Conditioned reflexes, Courier Corporation (2003).

[24] S.T. Tiffany, B.L. Carter, E.G. Singleton, Challenges in the manipulation, assessment and interpretation of craving relevant variables, Addiction 95 (8s2) (2000) 177-187.

[25] G. Andrews, P. Cuijpers, M.G. Craske, P. McEvoy, N. Titov, Computer therapy for the anxiety and depressive disorders is effective, acceptable and practical health care: a meta-analysis, PLoS One 5 (10) (2010) e13196.

[26] M.E. Saladin, K.T. Brady, K. Graap, B.O. Rothbaum, A preliminary report on the use of virtual reality technology to elicit craving and cue reactivity in cocaine dependent individuals, Addict Behav 31 (2006) 1881-1894.

[27] C. Culbertson, S. Nicolas, I. Zaharovits, E.D. London, R. Garza, A.L. Brody, et al., Methamphetamine craving induced in an online virtual reality environment, Pharmacol. Biochem. Behav. 96 (2010) 454-460. 
[28] S.H. Lee, D.H. Han, S. Oh, I.K. Lyoo, Y.S. Lee, P.F. Renshaw, et al., Quantitative electroencephalographic (qEEG) correlates of craving during virtual reality therapy in alcohol-dependent patients, Pharmacol. Biochem. Behav. 91 (2009) 393-397.

[29] M.G. Kushner, C. Donahue, S. Sletten, P. Thuras, K. Abrams, J. Peterson, B. Frye, Cognitive behavioral treatment of comorbid anxiety disorder in alcoholism treatment patients: presentation of a prototype program and future directions, J. Ment. Health 15 (6) (2006) 697-707.

[30] P.S. Bordnick, H.L. Copp, A. Traylor, K.M. Graap, B.L. Carter, A. Walton, Reactivity to cannabis cues in virtual reality environments, J. Psychoactive Drugs. 41(2) (2009) 105-112.

[31] B.L. Carter, P.S. Bordnick, A. Traylor, S.X. Day, M. Paris, Location and longing: the nicotine craving experience in virtual reality, Drug Alcohol Depend. 95 (1) (2008) 73-80

[32] H.C. Fox, K.L. Bergquist, K. Hong, R. Sinha, Stress-induced and alcohol cue-induced craving in recently abstinent alcohol-dependent individuals, Alcohol Clin. Exp. Res. 31 (3) (2007) 395-403.

[33] J. Sharry, M. Mcdermott, J. Condron, Relax to win: treating children with anxiety problems with a biofeedback video game? J. Irish Assoc. Counsel. Psychotherapy 2 (25) (2003) 22-25.

[34] C.M.M. Licht, E.J.C. de Geus, R. van Dyck, B.W.J.H. Penninx, Association between Anxiety Disorders and Heart Rate Variability in The Netherlands Study of Depression and Anxiety (NESDA), Psychosom. Med. 71 (5) (2009) 508-518.

[35] P. Melillo, M. Bracale, L. Pecchia, Nonlinear heart rate variability features for real-life stress detection. Case study: students under stress due to university examination, Biomed. Eng. Online 10 (1) (2011) 96.

[36] N. Sharma, T. Gedeon, Objective measures, sensors and computational techniques for stress recognition and classification: a survey, Comput. Methods Programs Biomed. 108 (2012) 1287-1301.

[37] ICD-10, International statistical classification of diseases and related health problems 10th revision, http://apps.who.int/classifications/icd10/browse/2010/ en accessed 15.04.12.

[38] S.H. Fairclough, Fundamentals of physiological computing, Interact. Comput. 21 (1) (2009) 133-145

[39] J.T. Cacioppo, L.G. Tassinary, G. Berntson, Handbook of Psychophysiology, Cambridge University Press, 2007.

[40] S. Mota, R.W. Picard, Automated posture analysis for detecting learner's interest level, in: Computer Vision and Pattern Recognition Workshop, CVPRW'03. Conference on IEEE, 2003, p. 49.

[41] G. Berna, L. Ott, J.L. Nandrino, Effects of emotion regulation difficulties on the tonic and phasic cardiac autonomic response, PLoS One 9 (7) (2014) e102971.

[42] J. Scheirer, R. Fernandez, J. Klein, R.W. Picard, Frustrating the user on purpose: a step toward building an affective computer, Interact. Comput. 14 (2002) 93-118.

[43] J. Sharry, M. McDermott, J. Condron, Relax to win treating children with anxiety problems with a biofeedback video game, Eisteach 2 (2003) 22-26.

[44] P. Rani, N. Sarkar, C.A. Smith, Affect-sensitive human-robot cooperation-theory and experiments, in: IEEE International Conference on Robot Automation, 2003, pp. 2382-2387.

[45] A.T. Beck, N. Epstein, G. Brown, R.A. Steer, An inventory for measuring clinical anxiety: psychometric properties, J. Consult. Clin. Psychol. 56 (6) (1988) 893.

[46] J.R. Landis, G.G. Koch, The measurement of observer agreement for categorical data, Biometrics 33 (1) (1977) 159-174.

[47] M. Dyck, M. Winbeck, S. Leiberg, Y. Chen, R.C. Gur, K. Mathiak, Recognition profile of emotions in natural and virtual faces, PLoS One 3 (11) (2008) e3628.

[48] G. Riva, A. Gorini, A. Gaggioli, The intrepid project - biosensor-enhanced virtual therapy for the treatment of generalized anxiety disorders, Stud. Health Technol. Inform. 142 (2009) 271-276.

[49] A. Gorini, G. Riva, Virtual reality in anxiety disorders: the past and the future, Expert Rev. Neurother. 8 (2008) 215-233.

[50] T.G. Plante, S. Cage, S. Clements, A. Stover, Psychological benefits of exercise paired with virtual reality: outdoor exercise energizes whereas indoor virtual exercise relaxes, Int. J. Stress Manag. 13 (2006) 108-117.

[51] F.J. Keefe, D.A. Huling, M.J. Coggons, D.F. Keefe, M.Z. Rosenthal, N.R. Herr, et al., Virtual reality for persistent pain: a new direction for behavioral pain management, Pain 153 (2012) 2163-2166.

[52] F. Spyridonis, J. Gawronski, G. Ghinea, A.O. Frank, An interactive 3-D application for pain management: results from a pilot study in spinal cord injury rehabilitation, Comput. Methods Programs Biomed. 108 (1) (2012) 356-366.

[53] J. Crain, Hypnosis and biofeedback for orofacial pain management, Orofacial Pain (2014) 115-131.
[54] K. Kim, S.I. Kim, K.R. Cha, J. Park, M.Z. Rosenthal, J.J. Kim, et al., Development of a computer-based behavioral assessment of checking behavior in obsessivecompulsive disorder, Compr. Psychiatry 51 (2010) 86-93.

[55] S. Cho, J. Ku, Y.K. Cho, I.Y. Kim, Y.J. Kang, D.P. Jang, et al., Development of virtual reality proprioceptive rehabilitation system for stroke patients, Comput. Methods Programs Biomed. 113 (1) (2013) 258-265.

[56] J.M.I. Zannatha, A.J. Tamayo, A.D. Sánchez, J.E. Delgado, L.E. Cheu, W.A. Arévalo, Development of a system based on 3D vision, interactive virtual environments, ergonometric signals and a humanoid for stroke rehabilitation, Comput. Methods Programs Biomed. 112 (2013) 239-249.

[57] D. Avola, M. Spezialetti, G. Placidi, Design of an efficient framework for fast prototyping of customized human-computer interfaces and virtual environments for rehabilitation, Comput. Methods Programs Biomed. 110 (2013) 490-502.

[58] A.C. Traylor, D.E. Parrish, H.L. Copp, P.S. Bordnick, Using virtual reality to investigate complex and contextual cue reactivity in nicotine dependent, Addict. Behav. 36 (2011) 1068-1075.

[59] K. Kim, M.Z. Rosenthal, D.J. Zielinski, R. Brady, Effects of virtual environment platforms on emotional responses, Comput. Methods Programs Biomed. 113 (2014) 356-366.

[60] G. Riva, E. Molinari, F. Vincelli, Interaction and presence in the clinical relationship: virtual reality (vr) as communicative medium between patient and therapist, IEEE Trans. Inf. Technol. Biomed. 6 (3) (2002) 198-205.

[61] B. Herbelin, F. Riquier, D. Thalmann, F. Vexo, Virtual reality in cognitive behavioral therapy: study on social anxiety disorder, in: Proceedings of the 25' Annual Intemalional Conference of the IEEE EMBS Cancun, Mexico, 2003, pp. $17-21$.

[62] P.L. Anderson, E. Zimand, L. Hodges, B.O. Rothbaum, Cognitive behavioral therapy for public speaking anxiety using virtual reality for exposure, Depress. Anxiety. 22 (2005) 156-158.

[63] E. Zimand, P. Anderson, G. Gershon, K. Graap, L. Hodges, B. Rothbaum, Virtual reality therapy: innovative treatment for anxiety disorders, Prim. Psychiatry 9 (7) (2003) 51-54

[64] T.D. Parsons, A.A. Rizzo, Affective outcomes of virtual reality exposure therapy for anxiety and specific phobias: a meta-analysis, J. Behav. Ther. Exp. Psychiatry 39 (2008) 250-261.

[65] Y. Shi, M.H. Nguyen, P. Blitz, B. French, S. Fisk, F. De la Torre, T. Kamarck, Personalized stress detection from physiological measurements, in: Proceedings of the 2nd International Symposium on Quality of Life Technology, 2010.

[66] G. Rigas, Y. Goletsis, D.I. Fotiadis, Real-time driver's stress event detection, IEEE Trans Intell Transp Syst 13 (1) (2012) 221-234.

[67] A. Sano, R. Picard, Stress recognition using wearable sensors and mobile phones, in: Humaine Association Conference on Affective Computing and Intelligent Interaction, 2013, pp. 671-676.

[68] P. Ren, A. Barreto, J. Huang, Y. Gao, F.R. Ortega, M. Adjouadi, Off-line and online stress detection through processing of the pupil diameter signal, Ann. Biomed. Eng. 42 (1) (2014) 162-176.

[69] D. Giakoumis, D. Tzovaras, G. Hassapis, Subject-dependent biosignal features for increased accuracy in psychological stress detection, Int. J. Hum. Comput. Stud. 71 (4) (2013) 425-439.

[70] R.R. Singh, S. Conjeti, R. Banerjee, An approach for real-time stress-trend detection using physiological signals in wearable computing systems for automotive drivers, in: Intelligent Transportation Systems (ITSC), 2011 14th International IEEE Conference on, 2011, pp. 1477-1482.

[71] A. de Santos Sierra, C.S. Ávila, J.G. Casanova, G.B.D. Pozo, A stress-detection system based on physiological signals and fuzzy logic, IEEE Trans. Ind. Electron. 58 (10) (2011) 4857-4865.

[72] J. Bakker, M. Pechenizkiy, N. Sidorova, What's your current stress level? Detection of stress patterns from GSR sensor data, in: Data Mining Workshops (ICDMW), 2011 IEEE 11th International Conference on IEEE, 2011, pp. 573-580.

[73] W. Wu, Y. Lee, Combination of wearable multi-biosensor platform and resonance frequency training for stress management of the unemployed population, Sensors 12 (2012) 13225-13248.

[74] P. Karthikeyan, M. Murugappan, S. Yaacob, Detection of human stress using short-term ECG and HRV signals, J. Mech. Med. Biol. 13 (2) (2013) 1350038.

[75] R.R. Singh, S. Conjeti, R. Banerjee, A comparative evaluation of neural network classifiers for stress level analysis of automotive drivers using physiological signals, Biomed. Signal Process. Control. 8 (6) (2013) 740-754.

[76] R. Castaldo, P. Melillo, U. Bracale, M. Caserta, M. Triassi, L. Pecchia, Acute mental stress assessment via short term HRV analysis in healthy adults: a systematic review with meta-analysis, Biomed. Signal Process. Control. 18 (2015) 370-377. 